\title{
Examining the relationship between informal science experiences and physics identity: Unrealized possibilities
}

\author{
Zahra Hazari, ${ }^{1,2,3,{ }^{*}}$ Remy Dou $\odot,{ }^{1,2}$ Gerhard Sonnert๑, ${ }^{4}$ and Philip M. Sadler® ${ }^{4}$ \\ ${ }^{1}$ Department of Teaching and Learning, Florida International University, Miami, Florida 33199, USA \\ ${ }^{2}$ STEM Transformation Institute, Florida International University, Miami, Florida 33199, USA \\ ${ }^{3}$ Department of Physics, Florida International University, Miami, Florida 33199, USA \\ ${ }^{4}$ Science Education Department, Harvard-Smithsonian Center for Astrophysics, \\ Cambridge, Massachusetts 02138, USA
}

(Received 4 March 2021; accepted 18 November 2021; published 20 January 2022)

\begin{abstract}
Both in physics education and in science education more generally concerns exist that formal K-12 education structures limit and, in some cases, diminish students' interest and agency in these fields. Many stakeholders have turned to informal learning experiences as a means to inspire young people to pursue continual learning in these fields in ways that foster creativity and self-determination. While research exists on the effect of these informal science experiences on students' science identities and broader science, technology, engineering, and math (STEM) identities, little is known about how specific informal science education experiences relate to students' physics identity - a construct strongly associated with physics career choice. The current study contributes to the literature by examining the effect of several informal science experiences on students' physics identity. Drawing on data from a national survey administered to students in required English courses at 27 colleges and universities across the US $(N=15847)$, we used multiple regression to test the relationship between informal science experiences in various topical areas at two educational levels (K-8 and 9-12) and students' physics identity, while controlling for science background and demographics. The results reveal positive effects for stereotypic informal experiences in physical science (e.g., tinkering, competitions) as well as for talking science with friends or family. In addition, there were negative relationships between biology-related experiences (at both levels) and physics identity. Group comparisons further revealed that female students were more likely to report participating in biology-related activities and less likely to report participating in tinkering, STEM competitions, and talking science with friends or family. Students who identified themselves as Black or Hispanic were also less likely than those of other racial or ethnic groups to report tinkering and talking science with friends or family. We use this evidence to build the case that informal learning experiences in physics should move beyond stereotypic activities, increase accessibility, facilitate discourse with family or friends, and focus on interdisciplinary experiences that better engage young participants with a wide range of interests that are connected to physics.
\end{abstract}

DOI: 10.1103/PhysRevPhysEducRes.18.010107

\section{INTRODUCTION}

It has been a pressing concern in physics and science education that students' career interests in these fields decline across the K-12 spectrum and that students from vulnerable populations become more marginalized in physics and science during the K-12 time period [1-4]. As science learning becomes more formalized in schooling

\footnotetext{
Corresponding author. zhazari@fiu.edu

Published by the American Physical Society under the terms of the Creative Commons Attribution 4.0 International license. Further distribution of this work must maintain attribution to the author(s) and the published article's title, journal citation, and DOI.
}

and the content becomes more specific and technically focused, students are limited in their ability to engage in activities that harness their own interests and innovative potential [5-8]. Thus, the broader education system has often relied on informal science education as a means towards engaging students' interests and providing less prescriptive activities for the purpose of fostering science agency and identity development [9-11]. In physics, however, it is unclear how effective different informal science education initiatives have been for fostering physics identity. This is important to consider given the promise of informal science education as a bastion for disciplinary identity development as well as the rapid increase of informal science education programming $[12,13]$.

The National Research Council in the U.S., which guides cooperation between government, education, industry, and 
research organizations to address critical national and global challenges, defines informal science education (ISE) as science learning that occurs in nonschool settings [10]. Over the years, this definition has been applied, both coarsely and with nuanced meanings, to similar phrases, including out-of-school (or "out-of-school-time") learning, lifelong learning, everyday learning, and free-choice learning. The settings in which informal learning occurs, particularly in science, vary greatly. These may include traditional informal learning settings, including museums, science centers, zoos, and aquariums, but also other settings including web-based interfaces (e.g., online forums, YouTube), makerspaces, after-school clubs, camps, big screen cinemas, other media (e.g., television, books), citizen science groups, hobbies at home, and a myriad of other possible settings and formats.

In the past decade, there has been a rapid increase of ISE programming in these various contexts [12-14]. ISE educators have also begun to focus more on how to engage households and communities in the process so that students can intersect their growing science identities with their home and community cultures and experiences [15-17]. While research exists on the effect of ISE experiences on students' science identities and broader science, technology, engineering, and math (STEM) identities [10,18-22], little is known about how ISE experiences broadly affect students' development of physics identities. This study provides a unique contribution because of the national scope of the data utilized and the ability to reveal systemic trends with respect to how certain K-12 level ISE experiences are related to college students' physics identity as well as how significant ISE experiences are distributed such that certain groups continue to be marginalized.

\section{DISCIPLINARY IDENTITY DEVELOPMENT}

Our work is guided by a disciplinary identity framework, specifically physics identity. In this context, disciplinary identity is defined as how students see themselves with respect to a discipline as they navigate experiences with that discipline $[23,24]$. These experiences shape students' interests and feelings of recognition, which in turn affect their disciplinary identities [20]. For example, if students start to become interested in physics or feel recognized by others as being capable of doing physics, then they will likely begin to see physics as part of who they are. In the language of students, they might refer to themselves as a "physics person" [24]. Since interest and recognition have been found to be central to disciplinary identity development for broad student populations [25-27], the next two sections review prior work on students' interest and recognition, particularly with respect to persistence and identity development. We focus on the importance of precollege experiences because the current study examines ISE prior to college.

\section{A. Interest prior to college}

Disciplinary interests have been a topic of research for decades and these interests have been strongly tied to developing disciplinary identities, particularly at early stages for learners and students [24-28]. This prior identity research has posited identity development as a mediating process between interest and career choice. Even though interest has been strongly tied to disciplinary identity development and subsequently long-term persistence, most studies on interest in science focus on examining the relationship between interest and persistence more directly [29-31]. For example, a study of STEM students in college found that when they were in high school they had already taken steps associated with degree attainment, including taking more science courses, as well as exhibiting both positive interest and attitudes toward particular STEM careers [30]. For students who earn physical science degrees, analysis of longitudinal data has shown that those who expressed an interest in pursuing science careers by 8th grade were 3.4 times more likely to have earned those degrees than were those who did not have that expectation in 8th grade [31]. Furthermore, a study drawing on 116 interviews of scientists and graduate students in physics and chemistry found that $65 \%$ of those interviewed, regardless of gender, indicated that they developed an interest in physics and chemistry topics prior to middle school [29]. Of these, physicists were more likely to have developed an interest in their field prior to middle schoolslightly over $80 \%$ of the physics sample. However, among women physicists and women undergraduates in physics, the largest fractions report having become interested during high school [32]. The above studies indicate that interest and goal setting in physics careers start much earlier than at the time students select their college major.

Critical to sustaining interest in STEM careers is, in fact, having developed that interest early on. Drawing on national survey data from college students, one study found that those who reported an interest in STEM careers at the beginning of high school were more likely than those who did not to be interested in STEM careers at the end of high school [4]. Moreover, students who reported having an interest in physics careers specifically at the beginning of high school were more likely than any other group of students to report a STEM career interest at the end of high school, although not necessarily physics careers. Despite this early development of interest in physics, studies also indicate that science interest for many students decreases as they progress through the K-12 stages, and that this decrease is more pronounced for individuals from groups minoritized in science fields $[3,33,34]$. In addition, many U.S. studies have demonstrated gendered patterns in experience and interest towards the physical sciences that favor male students as early as elementary school [35-39].

While physics is often part of the K-8 curriculum in the United States, as reflected in the Next Generation Science 
Standards (NGSS), much of this content gets taught by teachers who have little prior preparation in physics and, in some cases, in science overall [40-42]. Furthermore, teachers at early levels are bound by curricular constraints that prioritize literacy and mathematics [43]. As such, Aschbacher, Ing, and Tsai [44] as well as others (e.g., Ref. [10]) suggest turning to informal experiences as a way of enhancing students' scientific interests, knowledge, and skills. In terms of interest, ISE experiences have been found to be critical for the development of students' current and future interest in STEM, as well as their subsequent STEM identity development $[6,7,13,17,33,45,46]$. In addition, because ISE is not bound by curricular constraints and assessment requirements the way traditional classrooms are, there are more opportunities to incorporate students' personal interests in these spaces. However, ISE is optional and frequently cost prohibitive. Thus, it is often the case that students who participate are the ones who are already interested or privileged, which limits the possibilities of engaging more students, including minoritized groups, in physics [47-51].

\section{B. Recognition prior to college}

As students navigate experiences in science, in this case physics, they position themselves in certain ways and make bids to be recognized as certain kinds of people [52]. In these circumstances, how they are recognized by others is critical for how they identify themselves. Studies have found that meaningful recognition by others in physics is critically important for physics identity construction [32,53-55]. The accumulation of recognition in a discipline over the school years can assist in stabilizing or "thickening" disciplinary identity, which then feeds into feeling recognized and identifying with that discipline in the future [56]. Furthermore, prior work has found that recognition is critical for women and other minoritized populations $[27,32,33,54,55,57,58]$. In physics, recognition has been found to be particularly important for women's physics identity even though women report significantly less frequently than men that they are recognized by others in physics [27].

Studies have found that recognition by classmates and teachers is critical for disciplinary and academic identity development, particularly for female students and other minoritized populations who may not be recognized in science outside of school and mainly draw on resources within institutional environments $[32,59,60]$. This is also true in physics, particularly for women $[32,61,62]$. The importance of such recognition for students from minoritized ethnic or racial groups is highlighted in the experiences of a young African American student in the process of developing a science identity who felt "recognized... because his peers asked him for help when they needed it and always wanted to work with him" and his "teacher publicly recognized him as competent by creating spaces for his questions and insights during class discussions" (p. 482) [59]. However, many students often go unrecognized in classroom spaces for their skills and abilities $[1,7,33]$. Thus, disciplinary recognition should not be limited to the classroom but extend to spaces outside of school where students are afforded opportunities to engage in informal science [6-8,11,19,33].

There are some critical aspects of recognition in informal spaces to consider. Although informal spaces create opportunities for students to be recognized in ways that they are not recognized in traditional classrooms, this may not be perceived by students as "science" recognition, and often these informal spaces do not meaningfully recognize culturally diverse students' perspectives $[5,48,49,63-66]$. The first aspect posits that since the activities in informal science spaces are less structured and can provide greater opportunities for students to develop agency, they do not resemble "school science" and may not be perceived as doing science by the participants. As for the second aspect, if activities in informal spaces are extensions of school science (e.g., science fair, enrichment projects) that promote normative western ways of doing science and being a scientist, then they may not create new opportunities for students from diverse backgrounds to be recognized [48,49,63-66]. In other words, students who already excel in physics class and are recognized for excelling will likely also be recognized for excelling in those informal physics activities.

\section{IMPORTANCE OF INFORMAL SCIENCE EDUCATION TO DISCIPLINARY IDENTITY DEVELOPMENT}

Work on science identity has steadily grown in the last two decades, with an increasing focus on informal science education $[20,28,51,57,67]$. The research in this area highlights opportunities for identity development that are enabled through informal spaces but are not available through traditional school science. First, students' interest can be focused on and developed in ways that are unavailable in traditional classrooms with prescribed curricula $[7,10]$. Second, students' skills and abilities can be developed and recognized in ways that do not typically occur in science classrooms [5-7] and there is a need to broaden perspectives to include diverse cultures [48,49,63-66]. Third, students' communities (parents, family members, siblings, friends, etc.) can be leveraged in informal spaces and activities can span locations, including home, outdoors, museums, etc. $[8,15,17,20,67]$. Finally, there is a greater affordance in informal spaces for student agency where students design, direct, implement, and communicate scientific practice in ways that are empowering to themselves [5-7]. Given these possibilities, it is not surprising that informal education is positioned as a tremendous resource for disciplinary identity development and that 
considerable funding, both federal and otherwise, is devoted to these efforts.

Whereas the theoretical possibilities are considerable, it is not well understood whether informal experiences indeed have a significant impact on the physics identity development of students. Several existing studies explore informal science learning, but link participants' experience to development of broader science or STEM identities, as opposed to physics identity in particular [15,18-21]. Moreover, although a few studies specifically address identity development in informal learning environments as it relates to the physical sciences, such as engineering identity $[67,68]$ and physics identity [69], most of these studies focus on an in-depth qualitative examination of specific contexts with smaller numbers of participants. Furthermore, there is a lot of variability and complexity in the way ISE is implemented in physics [70]. Thus, together with qualitative work that unravels the nuances, more quantitative work is also necessary for understanding large-scale patterns and trends that reveal broader systemic issues. In addition, how various types of informal experiences affect students' physics identity and when these experiences occur is relatively underexplored. As such, this study examines the effect of different types of informal experiences at different levels (grades K-8, and 9-12) on students' physics identity early in college.

\section{LEVERAGING QUANTITATIVE METHODS WITH CRITICAL PERSPECTIVES}

In this work, we leverage quantitative methods with a critical perspective to better understand educational structures that serve to privilege certain students and how informal science education supports these structures or disrupts them in physics. Our goal is not to uncover racism or sexism, which have been argued to be inherent in the ontological and epistemological development of the discipline [71]. Instead, it is to examine the possible role of ISE, as it is currently implemented within the structures, because ISE has been held up as an avenue for disrupting structures in science or physics that marginalize certain groups. Thus, in interpreting our results, if a positive effect is found for certain ISE experiences on physics identity, we do not necessarily see it as a recommendation for increased implementation of that ISE experience but rather as a point for further questioning the educational structures. In addition, this work is correlational. Hence, while we might pose potential hypotheses, the work is not claiming to establish deterministic causal inferences. In complex human systems with many changing and interacting factors, it is open to question how meaningful these types of inferences are.

Furthermore, we did not impose an explicit meaning of "physics" on the students that were surveyed as part of this study. They reported whether they were interested and recognized in physics based on their own construction of what physics is. Although this meaning may have been imposed upon them by traditional structures (e.g., physics class content or practice), we do not presuppose that a uniform meaning existed among the students. In addition, we recognize that quantitative studies do not capture the nuanced experiences of individuals and thus are severely limited in their capability to uncover a deep and meaningful personal understanding of experiences. As such, our goal is not to achieve this deeper understanding but to examine the broader structural trends that might support and promote certain experiences over others. Increasing numbers of quantitative studies are taking more critical stances toward the use and interpretation of quantitative methods that seek to disrupt oppressive structures [71-74]. For example, QuantCrit draws on theoretical principles from critical race theory to provide more equitable guidelines for the use and analysis of quantitative data [72]. It is important to note that cross-sectional quantitative results are merely snapshots of a structure; they are not etched in stone nor do they depict individual realities. Nevertheless, they can be used to interrogate and disrupt the structure with the goal of moving towards a more equitable physics education. This is the approach taken in this paper with the goal of examining ISE and how it might reinforce or disrupt inequitable structures in physics education.

\section{RESEARCH QUESTIONS}

To better understand the relationships within the current structures between college students' physics identity and the kinds of informal learning experiences they report in prior years, we analyzed data from a national survey with the intent to address the following research questions:

RQ1. What types of informal science experiences in the early and late schooling years are related to college students' physics identity?

RQ2. Do certain minoritized groups in physics (female, Black, and Hispanic students) report significant experiences at different rates than do other students?

\section{METHODS}

Drawing on data from a retrospective cohort survey study of college students, we examined the effect of informal science education experiences within two time ranges (grades K-8 and 9-12) on students' physics identity. The survey was developed as part of the Outreach Programs and Science Career Intentions project, which focused on understanding how out-of-school science education programming affects students' pursuit of science-related careers. The survey included items on student demographics, academics, participation in ISE activities across multiple grade levels and physics identity items (specifically, interest and recognition in physics). We summarize the specific variables used in this study in the sections below. Many of the ISE experience items were similar to items previously used on other surveys of students [35,75]. 
An advisory team of science education researchers was involved in establishing face and content validity for the survey. The survey as a whole yielded a reliability of 0.73 after a test-retest study with 57 college students. Prior work has also provided evidence of the survey's reliability and validity [20].

In Fall 2013, the survey was administered to 15847 students in required English courses at 27 colleges and universities located in 20 different states. The colleges and universities were institutions that had previously been funded by the Science, Technology, Engineering, and Mathematics Talent Expansion Program of the National Science Foundation. Since students in required English courses represent a very broad cross section of the population of college students, the study was able to capture a large variation in experiences of students ranging from those with heavy prior physics exposure to those with little exposure. The majority of respondents, $72 \%$, were first year college students, while $18 \%$ reported they were second year or higher and $10 \%$ did not report their year in college. Respondent demographics (i.e., gender, race, ethnicity) mirrored that of the national student population [76]. Among the respondents, 51\% self-identified as female, $40 \%$ as male, and $9 \%$ selected neither female nor male. In terms of race or ethnicity, 57\% self-identified as white, $11 \%$ as Asian or Pacific Islander, $11 \%$ as Black, $2 \%$ as American Indian or Alaska Native, and $14 \%$ as another race or ethnicity. Within the sample population, $18 \%$ identified as Hispanic. Note that respondents could identify as multiple races or ethnicities.

\section{A. Informal science education experience variables}

A series of informal STEM learning activities were presented to respondents who were then asked to mark whether they had participated in each of those activities at different times in their lives according to their grade level: K-4th, 5th-8th, 9th, 10th, 11th, 12th. For this study, we grouped responses across grades K-8 and grades 9-12, such that participants who indicated participating in the activity once or more were coded as " 1 " and those that did not engage in the activity were coded as " 0. ." The clustering into two time ranges (K-8 and 9-12) reduced colinearity issues that could arise during the analysis. (Note that we assessed multicollinearity issues in the regressions using variance inflation factors.)

The informal activities were further grouped according to disciplinary or topic similarity. Table I summarizes the specific ISE experiences captured by the survey and how they were combined into variables for analysis based on discipline or topic of activity. For example, the items "tinkered with mechanical devices" and "tinkered with electrical devices" were grouped into one variable (i.e., "tinkering with mechanical or electrical devices"). The grouping was performed by combining the responses across all items into a binary variable, such that students who denoted having participated in any of the activities within the group were given a score of " 1 ," otherwise they received a score of " 0 ." Some items were retained as unique variables. The final set of 8 topics included tinkering with mechanical or electrical devices, mixing chemicals or materials, watching or interacting with plant or animal behavior, observing or studying stars, participating in STEM groups, participating in STEM competitions, consuming STEM media, and talking science with friends and family. The final independent variables for ISE experiences included 16 variables representing each of the eight ISE experience variables (in Table I) reported across the two time ranges.

TABLE I. List of informal STEM learning activities presented to survey respondents. Activity items were grouped according to content or topic.

\begin{tabular}{|c|c|}
\hline Variables at K-8 and 9-12 (Grouped ISE Experiences) & Items on survey \\
\hline Tinkering with mechanical or electrical devices & $\begin{array}{l}\text { - Tinkered with mechanical devices (e.g., rifle, bow and arrow, car jack, } \\
\text { pulleys, wheelbarrow, sewing machine) } \\
\text { - Tinkered with electrical devices (e.g., cars, batteries and bulbs, } \\
\text { radio, TV) }\end{array}$ \\
\hline Mixing chemicals or materials & $\begin{array}{l}\text { - Mixed chemical or materials. Engaged with chemistry sets, kitchen } \\
\text { chemistry }\end{array}$ \\
\hline Watching or interacting with plant or animal behavior & $\begin{array}{l}\text { - Took care of or trained an animal } \\
\text { - Planted seeds, watched plants grow, watched animal behavior, collected } \\
\text { things in nature (e.g., butterflies, rocks) }\end{array}$ \\
\hline Observing or studying stars & - Observed or studied stars and other astronomical objects \\
\hline STEM groups & - Participated in science groups, clubs, camps \\
\hline STEM competitions & - Participated in science or math competition(s) \\
\hline STEM media & $\begin{array}{l}\text { - Read or watched nonfiction science } \\
\text { - Read or watched science fiction }\end{array}$ \\
\hline Talking science & - Talked with friends or family about science \\
\hline
\end{tabular}




\section{B. Demographic and background variables}

In addition to focusing on the ISE experiences, we also controlled for several demographic and background variables. These control variables included respondents' selfreported gender, race or ethnicity, parental education, home support for science, and prior academics (middle school mathematics and science grades; high school English, mathematics, and science grades; calculus course taking). These controls were included in our analyses because these particular factors have previously been found to significantly affect outcomes related to physics identity [24].

\section{Physics identity variable}

The dependent variable in our study was a proxy measure for physics identity. We measured participants' physics identity using seven previously validated items. Our physics identity items were adapted from prior work $[24,26]$ and comprised indicators for physics interest and recognition-two constructs that both theoretically and empirically contribute to a person's disciplinary identity and specifically physics identity $[26,27,32,53]$. Whereas performance or competence beliefs are also theorized as contributing to physics identity, these beliefs have been found to have an indirect contribution through interest and recognition for general student populations such as the one in this study [26,27]. Thus, our measure of physics identity focuses on the constructs of interest and recognition, which have been found to contribute to physics identity more directly for these populations. Physics interest was measured using three items, and sense of recognition as a physics person was measured using four items. The items are summarized in Table II. Students were asked to denote the extent to which they agreed or disagreed with each statement on an anchored scale from " 0 " to " 5 " with labels at the poles only (i.e., "No, not at all" on one end and "Yes, very much" on the other).

Results of a confirmatory factor analysis supported our grouping of the physics identity items into two major factors: interest and recognition. The CFA fit indices $(\mathrm{CFI}=0.99 ; \quad \mathrm{TLI}=0.99 ; \quad \mathrm{GFI}=0.99 ; \quad \mathrm{AGFI}=0.98 ;$
RMSEA $=0.055 ;$ SRMR $=0.009)$ meet recommended values [77]. Table II summarizes the standardized factor loadings, item reliability, construct reliability, and average variance extracted (AVE). They all meet recommended thresholds for establishing the convergent validity of the constructs (i.e., factor loadings $>0.5$; construct reliability $>0.7$; and AVE $>0.7$ ) [78]. The three items for physics interest were averaged, as were the four items for physics recognition. The mean value was $1.74( \pm 0.01 \mathrm{SE})$ for the physics interest construct and 1.19 ( $\pm 0.01 \mathrm{SE})$ for the physics recognition construct. The final physics identity measure was calculated by averaging the interest and recognition constructs. The mean value for the overall physics identity measure was $1.45( \pm 0.01 \mathrm{SE})$. To assess the criterion-related validity of the physics identity measure, we used a logistic regression to examine the measure's relationship with students' intentions of being a physicist. Students were asked on the survey to select their intended careers with "physicist" as an option. This variable was regressed on the physics identity measure. The result was highly significant (odds ratio $=3.1$, $p<0.001$ ) indicating that 1 unit increase in the physics identity measure corresponded to a 3 times higher odds of intending to be a physicist.

\section{Analytic approach}

All data analysis was conducted using R software [79]. We used blocked multiple regression models to examine the effect of ISE experiences on the physics identity measure while controlling for the aforementioned variables. To avoid bias from listwise deletion of missing data, we used multiple imputation to handle missingness. Multiple imputation is the most appropriate way of dealing with complex nonresponse in large survey data [80] so that bias is not introduced by single imputation or listwise deletion, and individuals' responses with some missingness are maintained and represented in the data analysis. It is recommended to set the number of imputations in the range of 20 to 100 , and we performed 100 imputations because it is better to have a greater number of imputations for unbiased estimates [81]. The data were imputed using

TABLE II. Standardized factor loadings, item reliabilities, construct reliabilities, and average variance extracted for physics identity constructs from confirmatory factor analysis.

\begin{tabular}{llccc}
\hline \hline Physics identity items & $\begin{array}{c}\text { Standardized factor } \\
\text { loading }\end{array}$ & $\begin{array}{c}\text { Item } \\
\text { reliability }\end{array}$ & $\begin{array}{c}\text { Construct } \\
\text { reliability }\end{array}$ & $\begin{array}{c}\text { Average variance } \\
\text { extracted }\end{array}$ \\
\hline Interest & - I am interested in learning more about physics & 0.93 & 0.86 & 0.96 \\
& - Topics in physics excite my curiosity & 0.95 & 0.90 & 0.90 \\
& - I enjoy learning about physics & 0.96 & 0.92 & 0.97 \\
Recognition & - My physics teachers see me as a physics person & 0.95 & 0.90 & 0.90 \\
& - My family sees me as a physics person & 0.95 & 0.90 & 0.88 \\
- My friends or classmates see me as a physics person & 0.94 & 0.93 & \\
\hline \hline
\end{tabular}

$N=12837$. 
the Amelia package in $\mathrm{R}$ [82]. Once the data were imputed, the Zelig package in $\mathrm{R}$ was used to build the blocked regression models $[83,84]$. The first model included only our control variables. Only significant control variables were retained and they became our control block. The second model included the control block and the ISE experience variables that indicated whether or not respondents had participated in the activities across the two different time periods described earlier (i.e., grades K-8 and 9-12). In other words, each of the ISE experiences (e.g., tinkering with mechanical or electrical devices) was entered into the models as two different variables denoting when the specific experience happened: K- 8 time period, and 9-12 time period. Students could report each experience in both, one, or none of these periods. Similar to the first model, only significant variables were retained. The second model addressed RQ1. Multicollinearity was assessed using variance inflation factors. For all models, multicollinearity for each variable was satisfactory $(<2.0)$. We also tested interaction effects between ISE experiences and identifying as female, Black, or Hispanic to ascertain whether certain ISE experiences had different effects on physics identity by group. To address RQ2, we ran logistic regressions to examine whether female, Black, or Hispanic students had different likelihoods of reporting each significant experience as compared with nonfemale, nonBlack, or non-Hispanic students, respectively.

\section{RESULTS}

The results of the blocked regressions are summarized in Table III. The results of model 1 with only significant control variables revealed a significant negative relationship between identifying as female and the physics identity proxy (Est $=-0.92, p<0.001$ ). This aligns with findings from prior studies $[20,24]$. Students who reported their race or ethnicities as Asian or Pacific Islander were more likely to identify with physics (Est $=0.16, p<0.001$ ). Also consistent with prior research [24], students who had greater home support for science (e.g., activities like visiting museums or zoos) were more likely to identify with the field of physics (Est $=0.16, p<0.001$ ). In addition, we found that students who had taken advanced mathematics courses and had performed better in middle and high school mathematics and science were more likely to positively identify with physics. The adjusted $R^{2}$ of model 1 indicates that the control block explained roughly $19 \%$ of the variance in the physics identity proxy.

TABLE III. Model 1 (controls) and model 2 (controls and ISE) regression results on physics identity with variables, estimates, significance levels, and standard errors.

\begin{tabular}{|c|c|c|c|c|}
\hline \multirow[b]{2}{*}{ Variables } & \multicolumn{2}{|c|}{ Model 1} & \multicolumn{2}{|c|}{ Model 2} \\
\hline & Estimate & Std. Error & Estimate & Std. Error \\
\hline Intercept & $0.49^{* * *}$ & 0.09 & $0.37^{* * *}$ & 0.09 \\
\hline \multicolumn{5}{|l|}{ Controls } \\
\hline Gender identity: Female & $-0.92^{* * *}$ & 0.03 & $-0.79^{* * *}$ & 0.03 \\
\hline Racial identity: Asian or Pacific Islander & $0.16^{* * *}$ & 0.04 & $0.11^{* *}$ & 0.04 \\
\hline Home support for science & $0.16^{* * *}$ & 0.01 & $0.10^{* * *}$ & 0.01 \\
\hline Middle school science grade & $0.21^{* * *}$ & 0.02 & $0.15^{* * *}$ & 0.02 \\
\hline Middle school math grade & $0.06^{* *}$ & 0.02 & $0.08^{* * * *}$ & 0.02 \\
\hline Last high school English grade & $-0.13^{* * *}$ & 0.02 & $-0.12^{* * *}$ & 0.02 \\
\hline Last high school math grade & $0.12^{* * *}$ & 0.02 & $0.11^{* * *}$ & 0.02 \\
\hline Taken calculus & $0.20^{* * *}$ & 0.04 & $0.18^{* * *}$ & 0.03 \\
\hline Taken AP calculus AB & $0.28^{* * * *}$ & 0.03 & $0.23^{* * *}$ & 0.03 \\
\hline Taken AP calculus BC & $0.52^{* * *}$ & 0.06 & $0.46^{* * *}$ & 0.05 \\
\hline \multicolumn{5}{|l|}{ Informal STEM Experiences } \\
\hline Tinkering $(\mathrm{K}-8)$ & & & $0.07^{* *}$ & 0.03 \\
\hline Tinkering (9-12) & & & $0.25^{* * * *}$ & 0.03 \\
\hline Mixing chemicals or materials $(\mathrm{K}-8)$ & & & $0.11^{* * * *}$ & 0.03 \\
\hline Mixing chemicals or materials (9-12) & & & $0.09^{* * *}$ & 0.03 \\
\hline Watched or interacted with plant or animal behavior $(\mathrm{K}-8)$ & & & $-0.14^{* * *}$ & 0.03 \\
\hline Watched or interacted with plant or animal behavior (9-12) & & & $-0.09^{* * *}$ & 0.03 \\
\hline Observed or studied stars $(9-12)$ & & & $0.17^{* * * *}$ & 0.03 \\
\hline STEM competitions $(9-12)$ & & & $0.15^{* * *}$ & 0.03 \\
\hline Talking science $(\mathrm{K}-8)$ & & & $0.16^{* * *}$ & 0.03 \\
\hline Talking science $(9-12)$ & & & $0.44^{* * *}$ & 0.03 \\
\hline Adjusted $\mathbf{R}^{2}$ & & 0.19 & & 0.27 \\
\hline
\end{tabular}




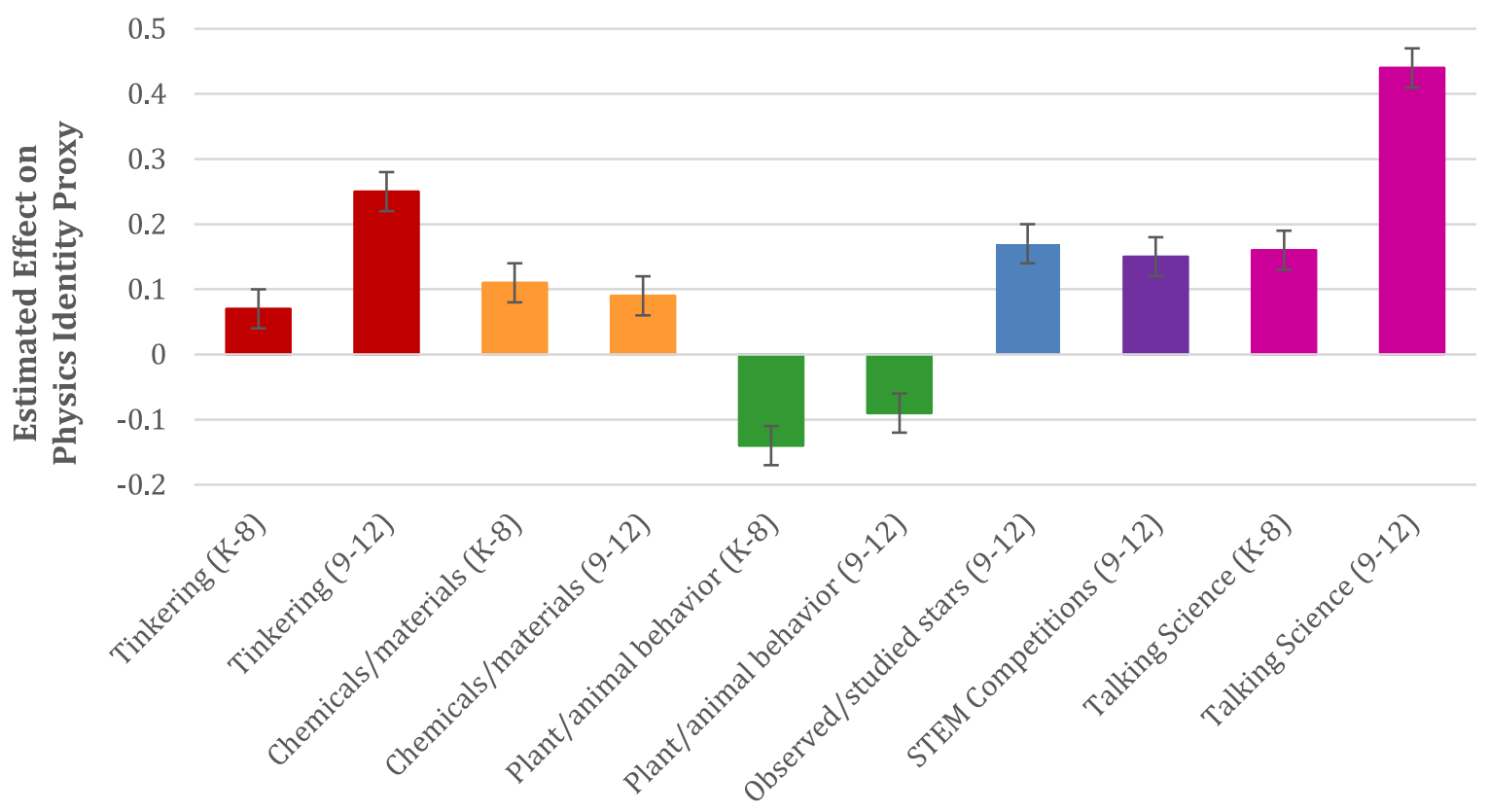

ISE Experiences (Model 2)

FIG. 1. . Estimated effects of significant ISE experiences (model 2) on physics identity proxy.

In terms of ISE experiences, the results of model 2 show significant positive relationships between physics identity and activities such as tinkering (at both K-8 and 9-12), mixing chemicals (at both K-8 and 9-12), observing stars (at 9-12), and participating in STEM competitions (at 912) (see Table III and Fig. 1). These types of experiences have traditionally been associated with the physical sciences. More of these significant experiences were at the high school level (9-12) rather than during the primary years, pointing to the later years as being formative (or salient) for physics identity in college. In addition to the positive effects of the aforementioned experiences, generally talking with friends and family about science during both K-8 and 9-12 was also positive and significant (Est $=0.16,0.44$, respectively, $p<0.001)$. In fact, talking about science in grades 9-12 had the largest effect relative to other ISE, even while controlling for factors such as home support and academics (see Table III).

While we did not expect to find a relationship between watching or interacting with plant or animal behavior and physics identity, there was a negative relationship for both $\mathrm{K}-8$ and $9-12$ levels (Est $=-0.14,-0.09$ respectively, $p<0.001)$. Thus, students who reported participating in these types of biology-related activities in grades K-8 or 912 were less likely to identify with physics. Finally, we tested interaction effects for the ISE experiences and identifying as female, Black, and Hispanic to ascertain whether certain experiences had a greater or lesser relationship with physics identity for these groups. We found significant interactions for talking science in grades 9-12 for female and Black students (see Supplemental
Material [85], Table S1). While the effect of talking science was significant and positive for female and Black students, this effect was smaller than for non-female and non-Black students respectively (see Supplemental Material [85], Figs. S1 and S2). No other significant interactions were found indicating that the effects of most of the ISE experiences were similar across the demographic groups considered. Thus, we summarized only the main effects model (Table III; see Supplemental Material [85] for interaction model).

Next, we compare the likelihood of each significant experience by group. Note that even if an experience is positively or negatively related to physics identity similarly for various groups, it may be experienced at different rates, i.e., certain groups may be more or less likely to have had that experience. To examine whether students from minoritized groups in physics reported experiencing significant ISE experiences at different rates than other students, logistic regressions were run to examine the likelihood of each significant ISE experience with each group identification. The results are summarized in Table IV. Female students were significantly less likely than non-females to report tinkering at both the K-8 and 9-12 levels. At the 9-12 level, they were less likely to report observing or studying stars, participating in STEM competitions, or talking science with friends and family. All of the experiences that female students were less likely to experience were positively associated with physics identity. Female students were more likely to report experiencing watching or interacting with plant or animal behavior at both the K-8 and 9-12 levels. Thus, female 
TABLE IV. Likelihood of reporting significant ISE experiences for female students, Black students, and Hispanic students.

\begin{tabular}{|c|c|c|c|c|c|c|c|c|c|}
\hline \multirow[b]{2}{*}{ ISE } & \multicolumn{3}{|c|}{ Female } & \multicolumn{3}{|c|}{ Black } & \multicolumn{3}{|c|}{ Hispanic } \\
\hline & Est & SE & OR & Est & SE & OR & Est & SE & OR \\
\hline Tinkering (K-8) & $-0.66^{* * *}$ & 0.03 & 0.52 & $-0.24^{* * *}$ & 0.05 & 0.79 & $-0.11^{* *}$ & 0.04 & 0.89 \\
\hline Tinkering $(9-12)$ & $-1.02^{* * *}$ & 0.03 & 0.36 & $-0.28^{* * *}$ & 0.05 & 0.76 & 0.02 & 0.04 & 1.02 \\
\hline Mixing chemicals or materials $(\mathrm{K}-8)$ & 0.07 & 0.04 & 1.07 & -0.13 & 0.06 & 0.88 & $-0.21^{* * *}$ & 0.06 & 0.81 \\
\hline Mixing chemicals or materials (9-12) & -0.05 & 0.04 & 0.95 & -0.05 & 0.05 & 0.95 & $0.11^{* *}$ & 0.04 & 1.12 \\
\hline Watched or interacted with plant or animal behavior $(\mathrm{K}-8)$ & $0.53^{* * *}$ & 0.04 & 1.69 & $-0.39^{* * *}$ & 0.05 & 0.67 & -0.09 & 0.04 & 0.91 \\
\hline Watched or interacted with plant or animal behavior (9-12) & $0.14^{* * *}$ & 0.03 & 1.16 & $-0.57^{* * *}$ & 0.05 & 0.57 & $-0.12^{* *}$ & 0.04 & 0.89 \\
\hline Observed or studied stars $(9-12)$ & $-0.21^{* * *}$ & 0.04 & 0.81 & $-0.20^{* *}$ & 0.06 & 0.82 & -0.02 & 0.05 & 0.98 \\
\hline STEM competition (9-12) & $-0.27^{* * *}$ & 0.04 & 0.77 & -0.16 & 0.07 & 0.86 & -0.05 & 0.05 & 0.96 \\
\hline Talking science $(\mathrm{K}-8)$ & 0.003 & 0.04 & 1.00 & $-0.25^{* * *}$ & 0.06 & 0.78 & $-0.12^{* *}$ & 0.05 & 0.88 \\
\hline Talking science (9-12) & $-0.24^{* * *}$ & 0.03 & 0.79 & $-0.43^{* * *}$ & 0.05 & 0.65 & $-0.13^{* *}$ & 0.04 & 0.88 \\
\hline
\end{tabular}

students were more likely to report an experience that was negatively related to physics identity. Students who identified as Black were less likely than non-Black students to report tinkering (at both K-8 and 9-12), observing or studying stars (at 9-12), and talking science (at both K-8 and 9-12), all of which were positively associated to physics identity. However, Black students were also less likely to report watching or interacting with plant or animal behavior (at both K-8 and 9-12), an ISE experience that was negatively related to physics identity. These results may indicate a more general lack of accessibility to STEM experiences, which has been previously reported for Black students [64]. In terms of positive experiences for physics identity, Hispanic students were less likely than nonHispanic students to report tinkering and mixing chemicals at the K-8 level and talking science at both the K-8 and 9-12 levels. They were more likely, however, to report mixing chemicals at the 9-12 level. In terms of negative experiences for physics identity, Hispanic students were less likely to report watching or interacting with plant or animal behavior at the 9-12 level. These results will be discussed further below.

\section{DISCUSSION}

Informal learning experiences, particularly within the STEM domains, have been promoted as a means to motivate interest in STEM fields [10,86-89]. The same has been observed in a more targeted way within physical science domains $[36,90]$. Yet these studies are often limited in both the types of informal learning activities examined and their ability to disaggregate these experiences across life stages. Our examination of national data from early college students provides a broad overview of the kinds of informal learning activities salient to college students' physics identity and the contribution of these activities across two different time periods (i.e., grades K-8 and 9-12) while taking into account a variety of factors previously associated with physics identity development.
This kind of study using a national dataset to examine the connection between ISE experiences and physics identity makes an important contribution to exposing and understanding larger systemic issues. In addition, we take a critical approach to better understand whether these activities are upholding or disrupting traditional structures rather than interpreting the results as an endorsement of certain activities or rejection of other activities. We also examine accessibility to activities for students from minoritized populations as an additional layer of critique.

Our findings revealed that participating in activities traditionally associated with the physical sciences positively related to physics identity. These experiences included tinkering with mechanical or electrical devices, mixing chemicals, observing stars, and participating in STEM competitions. Given the typical association of these activities with the physical sciences, it is not surprising to find that respondents who reported these experiences while growing up were more likely to identify with physics. Thus, the informal experiences likely served to reinforce typical constructions of physics identity rather than creating novel opportunities for physics identity development. We also found that talking about science with friends and family had a positive effect at both the K-8 and 9-12 levels, albeit a larger effect at 9-12. However, this effect was smaller for female and Black students (see Supplemental Material [85]) indicating that there may be a need to improve the mode and framing of discourse in physics. Intersectional and qualitative work is sorely needed to understand how talking science may be enacted differently and how the effect of this talk is limited by normative constructions of what it means to be a physics person.

In addition, we found that watching or interacting with plant or animal behavior at both time periods was negatively related to the physics identity of college students. Alternately stated, those who reported these biology-related experiences were more likely than other students in the sample to not identify with physics. One might expect that 
disciplinary experiences in another science should be positively related to physics identity (since physics is also a science) or at the very least, be unassociated with physics identity. Whereas a positive effect was observed for certain chemistry-related and astronomy-related experiences, this was not the case for the biology-related experience of watching or interacting with plant or animal behavior. This result highlights an important issue in the cultural construction of what it means to be a physics person as possibly being antithetical to certain biology-related activities. At the very least, these activities should not contribute to a disidentification with physics-especially given that these experiences do not explicitly posit physics as antithetical to biology. Yet, our findings show a negative relationship between participating in biology-related activities and college students' identification with physics. This dissonance between "physics people" and those who engaged in biology-related activities prior to college might indicate that cultural experiences likely set students on tracks that steer them in one direction or the other rather than allowing intersecting interests and pursuits. It may also create artificial barriers that impede the physics participation of students interested in biology or interdisciplinary pursuits.

To further understand how experiences might serve to privilege or disprivilege, we also examined the prevalence of the significant experiences for female students, Black students, and Hispanic students, as compared to those who did not identify with these groups. With the exception of mixing chemicals and early science talk $(\mathrm{K}-8)$, female students were less likely to report any of the experiences positively related to physics identity (tinkering, observing stars, STEM competitions, and later science talk). They were also more likely to report watching or interacting with plant or animal behavior at both levels, which was negatively related to physics identity. It is disheartening that the patterns of experience are consistent with decadesold research [36-39] despite many initiatives to increase informal learning experiences in physics-related areas for girls [91-96]. Furthermore, the results highlight the continued "gendering" of the sciences at early ages. Other decades-old work also found prevalent perceptions among students that life science is more appropriate for girls and physical science is more appropriate for boys [97]. These persistent issues may be rooted in the fact that physics education has typically taken a deficit-oriented approach that attempts to change girls (e.g., exposing them to more of the same traditional experiences, attempting to socialize them differently, or patch up feelings of deficits) rather than changing what constitutes engagement in physics and physics itself [98]. As such, it is not surprising that patterns of women's underrepresentation have remained relatively consistent for decades [99].

Students who identified as Black were significantly less likely to report most of the significant ISE experiences, except for mixing chemicals and STEM competitions. This includes both the experiences that were positively related to physics identity (tinkering, observing stars, talking science) and those that were negatively related (watching or interacting with plant or animal behavior). This may highlight a broader lack of availability of resources and experiences for students who identify as Black, particularly in physics [55]. For example, it has been found that Black students are less likely than white students to attend schools that offer physics $[100,101]$. Students who identified themselves as Hispanic were less likely to report certain significant experiences at the K-8 level, specifically tinkering, mixing chemicals, and talking science. Of these experiences, they were also less likely to report talking science at the 9-12 level, but more likely to report mixing chemicals. In addition, they were less likely at this later level to report watching or interacting with plant or animal behavior. These results indicate that Hispanic students may have less access to certain opportunities at earlier levels that are related to future physics identity construction. Prior research has highlighted a crucial function of ISE - to provide intersections with cultural or linguistic backgrounds of Hispanic parents so they can better connect with their children during ISE activities [65]. It is important to note that for both Black and Hispanic identifying students, the most significant experience at both time periods, talking science, was reported at lower rates than by other students. Female students reported it at lower rates than non-female students only at the 9-12 level, where talking science had a larger effect than any other experience at either time period.

The findings of this study suggest that informal learning experiences in physics likely reinforce traditional or stereotypic content or practices (e.g., tinkering with mechanical or electrical devices, observing or studying stars, STEM competition), fail to intersect in positive ways with the biological sciences, and continue to be less accessible to students from historically marginalized groups (particularly regarding tinkering and talking science). It is worth further exploring how informal physics experiences can be designed to engage those interested in biology in light of studies pointing to the biological sciences as more interesting and more inclusive fields for women and other minoritized groups in physics $[4,36,39,99,102,103]$. Furthermore, our analyses support prior findings [24] that female students' self-perceptions with respect to physics are considerably depressed when compared with the rest of the student population since identifying as female had the largest negative effect associated with physics identity in our model. Finally, it is important to note that there were nonsignificant ISE experiences as well, namely, STEM media and groups, clubs, and camps. Rather than missing opportunities, it may be worthwhile to reconsider how these types of experiences can be better leveraged to construct salient and relevant physics identities that connect with how youth see themselves. 
As with all research, there are several limitations to this work. While cross-sectional quantitative research can provide a snapshot of broad trends within structures, it lacks the nuance and depth provided by qualitative work. As such, the findings cannot elaborate on the nature of experiences reported by students or how or why they relate with physics identity. The measurements also do not deeply capture students' many identities or what it means to identify with different groups intersectionally (e.g., gender, race, ethnicity, generation, language, SES, religion, etc.). Furthermore, the results do not reflect patterns for every individual, nor do they predict outcomes for individuals. As such, they should not be used to make decisions or recommendations for individuals. Our critical perspective allows us to use the results to examine the broader structures and critique ways in which the analysis reveals these structures to be marginalizing and hegemonic. Finally, more nuanced physics identity work is needed on intersectional experiences, both informal and formal, with respect to gender, race, ethnicity, disability, language, class, generation, and many other identities that have been marginalized in physics. In addition, it is crucial for future work to focus on ways to reform or disrupt experiences toward more intersectionally constructed physics identities and redefine physics identities by promoting and embedding the voices, insights, and perspectives of those who have been historically marginalized.

As physics educators and education researchers, we have considerable work to do to address historic issues that have resulted in a culture of physics that creates boundaries and impedes diverse voices from contributing to defining the field, its content, and its practices. As Hyater-Adams et al. [62] point out, we need to connect research to "concrete changes in institutions and systems through the creation of informal science educational programs that take up pedagogies and content" from other spaces "in order to create a more inclusive physics education space." Furthermore, we need to begin to realize the possibilities that transformative ISE experiences can provide to engage the tremendous creative potential and new exploration or ideas that fresh minds can bring to the future of the field. It is unfortunate that cultural values in the field have been found to marginalize and impede ISE and its advancement, as well as those who participate in ISE. For example, Johnson et al. [104] found that "Physicists view outreach as outside of the scientific role and a possible threat to reputation" and that women were "more likely than men to participate in outreach, a commitment that often results in peer-based informal sanctions." The devaluing of outreach and informal science signifies a larger problem as does the use of informal science to reproduce the rigid culturally defined boundaries of physics.

\section{ACKNOWLEDGMENTS}

This study was supported by the National Science Foundation (NSF) Grant No. 1161052 as well as Grant No. 1721021 for theoretical development. Any opinions, findings, and conclusions or recommendations expressed in this material are those of the authors and do not necessarily reflect the views of the National Science Foundation.
[1] H. B. Carlone, C. M. Scott, and C. Lowder, Becoming (less) scientific: A longitudinal study of students' identity work from elementary to middle school science, J. Res. Sci. Teach. 51, 836 (2014).

[2] R. F. Lei, E. R. Green, S. J. Leslie, and M. Rhodes, Children lose confidence in their potential to "be scientists," but not in their capacity to "do science", Dev. Sci. 22, e12837 (2019).

[3] C. Riegle-Crumb, C. Moore, and A. Ramos-Wada, Who wants to have a career in science or math? Exploring adolescents' future aspirations by gender and race/ethnicity, Sci. Educ. 95, 458 (2011).

[4] P. M. Sadler, G. Sonnert, Z. Hazari, and R. Tai, Stability and volatility of STEM career interest in high school: A gender study, Sci. Educ. 96, 411 (2012).

[5] L. Archer, J. DeWitt, J. Osborne, J. Dillon, B. Willis, and B. Wong, "Doing" science versus "being" a scientist: Examining 10/11-year-old schoolchildren's constructions of science through the lens of identity, Sci. Educ. 94, 617 (2010).
[6] S. J. Basu and A. Calabrese Barton, How do urban minority youth develop a sustained interest in science?, J. Res. Sci. Teach. 44, 466 (2007).

[7] A. Calabrese Barton and K. Yang, The culture of power and science education: Learning from Miguel, J. Res. Sci. Teach. 37, 871 (2000).

[8] R. Elmesky, "I am science and the world is mine": Embodied practices as resources for empowerment, School Sci. Math. 105, 335 (2005).

[9] J.D. Adams and P. Gupta, Informal science institutions and learning to teach: An examination of identity, agency, and affordances, J. Res. Sci. Teach. 54, 121 (2017).

[10] National Research Council, Learning Science in Informal Environments: People, Places, and Pursuits (The National Academies Press, Washington, DC, 2009), 10.17226/12190.

[11] K. Riedinger and J. R. McGinnis, An investigation of the role of learning conversations in youth's authoring of 
science identities during an informal science camp, Int. J. Sci. Educ. Part B 7, 76 (2017).

[12] Center for the Advancement of Informal Science Education, A Resource Round-Up of 2019: The Year in Informal STEM Education (CAISE, Washington, DC, 2020), https://www.slideshare.net/informalscience/caise-year-inise-2019-final.

[13] J. H. Falk, S. Pattison, D. Meier, D. Bibas, and K. Livingston, The contribution of science-rich resources to public science interest, J. Res. Sci. Teach. 55, 422 (2018).

[14] K. Sacco, J. H. Falk, and J. Bell, Informal science education: Lifelong, life-wide, life-deep, PLoS Biol. 12, e1001986 (2014).

[15] R. Dou and H. Cian, The Relevance of Childhood Science Talk as a Proxy for College Students' STEM Identity at a Hispanic Serving Institution, Res. Sci. Educ. 50, 1 (2020).

[16] L. R. McClain and H. T. Zimmerman, Prior experiences shaping family science conversations at a nature center, Sci. Educ. 98, 1009 (2014).

[17] S. A. Pattison and L. D. Dierking, Early childhood science interest development: Variation in interest patterns and parent-child interactions among low-income families, Sci. Educ. 103, 362 (2019).

[18] A. C. Barton and E. Tan, We Be Burnin'! Agency, Identity, and Science Learning, J. Learn. Sci. 19, 187 (2010).

[19] H. B. Carlone, L. D. Huffling, T. Tomasek, T. A. Hegedus, C. E. Matthews, M. H. Allen, and M. C. Ash, 'Unthinkable' Selves: Identity boundary work in a summer field ecology enrichment program for diverse youth, Int. J. Sci. Educ. 37, 1524 (2015).

[20] R. Dou, Z. Hazari, K. Dabney, G. Sonnert, and P. Sadler, Early informal STEM experiences and STEM identity: The importance of talking science, Sci. Educ. 103, 623 (2019).

[21] R. M. Hughes, B. Nzekwe, and K. J. Molyneaux, The single sex debate for girls in science: A comparison between two informal science programs on middle school students' STEM identity formation, Res. Sci. Educ. 43, 1979 (2013).

[22] J. Moote, L. Archer, J. DeWitt, and E. MacLeod, Science capital or STEM capital? Exploring relationships between science capital and technology, engineering, and maths aspirations and attitudes among young people aged 17/18, J. Res. Sci. Teach. 57, 1228 (2020).

[23] N. Enyedy, J. Goldberg, and K. M. Welsh, Complex dilemmas of identity and practice, Sci. Educ. 90, 68 (2006).

[24] Z. Hazari, G. Sonnert, P. Sadler, and M.-C. Shanahan, Connecting high school physics experiences, outcome expectations, physics identity, and physics career choice: A gender study, J. Res. Sci. Teach. 47, 978 (2010).

[25] J. D. Cribbs, Z. Hazari, G. Sonnert, and P. M. Sadler, Establishing an explanatory model for mathematics identity, Child Development 86, 1048 (2015).

[26] A. Godwin, G. Potvin, Z. Hazari, and R. M. Lock, Identity, critical agency, and engineering: An affective model for predicting engineering as a career choice, J. Eng. Educ. 105, 312 (2016).
[27] R. M. Lock, Z. Hazari, and G. Potvin, Impact of out-ofclass science and engineering activities on physics identity and career intentions, Phys. Rev. Phys. Educ. Res. 15, 020137 (2019).

[28] K. A. Renninger, Interest and identity development in instruction: An inductive model, Educ. Psychol. 44, 105 (2009).

[29] A. V. Maltese and R. H. Tai, Eyeballs in the fridge: Sources of early interest in science, Int. J. Sci. Educ. 32, 669 (2010).

[30] A. V. Maltese and R. H. Tai, Pipeline persistence: Examining the association of educational experiences with earned degrees in STEM among U.S. students, Sci. Educ. 95, 877 (2011).

[31] R. H. Tai, C. Q. Liu, A. V. Maltese, and X. Fan, Planning early for careers in science, Science 312, 1143 (2006).

[32] Z. Hazari, E. Brewe, R. M. Goertzen, and T. Hodapp, The importance of high school physics teachers for female students' physics identity and persistence, Phys. Teach. 55, 96 (2017).

[33] A. Calabrese Barton, H. Kang, E. Tan, T. B. O’Neill, J. Bautista-Guerra, and C. Brecklin, Crafting a future in science: Tracing middle school girls' identity work over time and space, Am. Educ. Res. J. 50, 37 (2013).

[34] K. Skamp and M. Logan, Students' interest in science across the middle school years, Teach. Sci. 51, 8 (2005).

[35] S. J. Farenga and B. A. Joyce, What children bring to the classroom: Learning science from experience, School Sci. Math. 97, 248 (1997).

[36] A. Baram-Tsabari and A. Yarden, Girls' biology, boys' physics: Evidence from free-choice science learning settings, Res. Sci. Technol. Educ. 26, 75 (2008).

[37] Z. Hazari, P. M. Sadler, and R. H. Tai, Gender differences in the high school and affective experiences of introductory college physics students, Phys. Teach. 46, 423 (2008).

[38] M. G. Jones, A. Howe, and M. J. Rua, Gender differences in students' experiences, interests, and attitudes toward science and scientists, Sci. Educ. 84, 180 (2000).

[39] G. Sonnert, P. Sadler, and M. Michaels, Gender aspects of participation, support, and success in a state science fair, School Sci. Math. 113, 135 (2013).

[40] G. R. Hale, R. E. Lopez, A. M. Cavallo, and E. E. Gonzales, Increasing Physics Teacher Production by Replicating the UTeach Preparation Model and Awarding Noyce Scholarships, Sci. Educ. 8, 199 (2017).

[41] National Center for Education Statistics, Changes in Instructional Hours in Four Subjects by Public School Teachers of Grades 1 through 4 (U.S. Department of Education, Washington, DC, 2007).

[42] J. K. Olson, C. D. Tippett, T. M. Milford, C. Ohana, and M. P. Clough, Science teacher preparation in a North American context, J. Sci. Teach. Educ. 26, 7 (2015).

[43] J. S. Wills and J. H. Sandholtz, Constrained professionalism: Dilemmas of teaching in the face of test-based accountability, Teachers College Record 111, 1065 (2009)

[44] P. R. Aschbacher, M. Ing, and S. M. Tsai, Is science me? Exploring middle school students' STEM career aspirations, J. Sci. Educ. Technol. 23, 735 (2014). 
[45] J. H. Falk, M. Storksdieck, and L. D. Dierking, Investigating public science interest and understanding: Evidence for the importance of free-choice learning, Publ. Understand. Sci. 16, 455 (2007).

[46] E. E. Goff, K. L. Mulvey, M. J. Irvin, and A. HartstoneRose, The effects of prior informal science and math experiences on undergraduate stem identity, Res. Sci. Technol. Educ. 38, 272 (2020).

[47] K. P. Dabney, R. H. Tai, and M. R. Scott, Informal science: Family education, experiences, and initial interest in science, Int. J. Sci. Educ. Part B 6, 263 (2016).

[48] E. Dawson, Equity in informal science education: Developing an access and equity framework for science museums and science centres, Stud. Sci. Educ. 50, 209 (2014).

[49] E. Dawson, Social justice and out-of-school science learning: Exploring equity in science television, science clubs and maker spaces, Sci. Educ. 101, 539 (2017).

[50] L. Dionne, G. Reis, L. Trudel, G. Guillet, L. Kleine, and C. Hancianu, Students' sources of motivation for participating in science fairs: An exploratory study within the Canada-wide science fair 2008, Int. J. Sci. Math. Educ. 10, 669 (2012).

[51] P. Wulff, Z. Hazari, S. Petersen, and K. Neumann, Engaging young women in physics: An intervention to support young women's physics identity development, Phys. Rev. Phys. Educ. Res. 14, 020113 (2018).

[52] J. P. Gee, Identity as an Analytic Lens for Research in Education, Rev. Res. Educ. 25, 99 (2000).

[53] Z. Hazari and C. Cass, Towards meaningful physics recognition: What does this recognition actually look like?, Phys. Teach. 56, 442 (2018).

[54] A. J. Gonsalves, "Physics and the girly girl-There is a contradiction somewhere": Doctoral students' positioning around discourses of gender and competence in physics, Cult. Stud. Sci. Educ. 9, 503 (2014).

[55] S. Hyater-Adams, C. Fracchiolla, T. Williams, N. Finkelstein, and K. Hinko, Deconstructing Black physics identity: Linking individual and social constructs using the critical physics identity framework, Phys. Rev. Phys. Educ. Res. 15, 020115 (2019).

[56] P. A. Jackson and G. Seiler, Science identity trajectories of latecomers to science in college, J. Res. Sci. Teach. 50, 826 (2013).

[57] S. Rodriguez, K. Cunningham, and A. Jordan, STEM identity development for Latinas: The role of self-and outside recognition. J. Hisp. High. Educ. 18, 254 (2019).

[58] S. D. Simpkins, C. D. Price, and K. Garcia, Parental support and high school students' motivation in biology, chemistry, and physics: Understanding differences among Latino and Caucasian boys and girls, J. Res. Sci. Teach. 52, 1386 (2015).

[59] J. M. Kane, Young African American children constructing academic and disciplinary identities in an urban science classroom, Sci. Educ. 96, 457 (2012).

[60] E. Tan and A. Calabrese Barton, From peripheral to central, the story of Melanie's metamorphosis in an urban middle school science class, Sci. Educ. 92, 567 (2008).

[61] Z. Y. Kalender, E. Marshman, C. D. Schunn, T. J. Nokes-Malach, and C. Singh, Gendered patterns in the construction of physics identity from motivational factors, Phys. Rev. Phys. Educ. Res. 15, 020119 (2019).

[62] S. Hyater-Adams, C. Fracchiolla, N. Finkelstein, and K. Hinko, Critical look at physics identity: An operationalized framework for examining race and physics identity, Phys. Rev. Phys. Educ. Res. 14, 010132 (2018).

[63] B. M. J. Brayboy and A. E. Castagno, How might Native science inform "informal science learning"?, Cult. Stud. Sci. Educ. 3, 731 (2008).

[64] J. DeWitt and L. Archer, Participation in informal science learning experiences: The rich get richer?, Int. J. Sci. Educ. Part B 7, 356 (2017).

[65] I. Weiland, An exploration of hispanic mothers' culturally sustaining experiences at an informal science center, J. Res. Sci. Teach. 52, 84 (2015).

[66] E. Dawson, Equity, Exclusion and Everyday Science Learning: The Experiences of Minoritised Groups, (Routledge, London and New York, 2019), https://www .routledge.com/Equity-Exclusion-and-Everyday-ScienceLearning-The-Experiences-of-Minoritised/Dawson/p/ book/9780367662158.

[67] S. Pattison, I. Gontan, S. Ramos-Montañez, T. Shagott, M. Francisco, and L. Dierking, The identity-frame model: A framework to describe situated identity negotiation for adolescent youth participating in an informal engineering education program, J. Learn. Sci. 29, 550 (2020).

[68] S. A. Pattison, I. Gontan, S. Ramos-Montañez, and L. Moreno, Identity negotiation within peer groups during an informal engineering education program: The central role of leadership-oriented youth, Sci. Educ. 102, 978 (2018).

[69] C. Fracchiolla, B. Prefontaine, and K. Hinko, Community of practice approach for understanding identity development within informal physics programs, Phys. Rev. Phys. Educ. Res. 16, 020115 (2020).

[70] D. Izadi, J. Willison, K. Hinko, and C. Fracchiolla, Developing an organizational framework for informal physics programs, in Proceedings of the 2019 Physics Education Research Conference, Provo, UT (AIP, New York, 2019).

[71] N. M. Garcia, N. López, and V. N. Velez, QuantCrit: Rectifying quantitative methods through critical race theory, Race Ethn. Educ. 21, 149 (2018).

[72] D. Gillborn, P. Warmington, and S. Demack, QuantCrit: education, policy,'Big Data'and principles for a critical race theory of statistics, Race Ethn. Educ. 21, 158 (2018).

[73] F. K. Stage, Answering critical questions using quantitative data, New Dir. Instit. Res. 133, 5 (2007).

[74] B. Van Dusen and J. Nissen, Associations between learning assistants, passing introductory physics, and equity: A quantitative critical race theory investigation, Phys. Rev. Phys. Educ. Res. 16, 010117 (2020).

[75] C. L. Mason and J. B. Kahle, Student attitudes toward science and science-related careers, J. Res. Sci. Teach. 26, 25 (1989).

[76] J. McFarland, B. Hussar, X. Wang, J. Zhang, K. Wang, A. Rathbun, A. Barmer, E. Forrest Cataldi, and F. Bullock Mann, The Condition of Education 2018 (NCES 2018-144), U.S. Department of Education 
(National Center for Education Statistics, Washington, DC, 2018).

[77] J. F. Hair, W. C. Black, B. J. Babin, and R. E. Anderson, Multivariate data analysis: Pearson new international edition (Pearson Education Limited, Essex, 2014).

[78] C. Fornell and D. F. Larcker, Evaluating structural equation models with unobservable variables and measurement error, J. Mark. Res. 18, 39 (1981).

[79] $\mathrm{R}$ Core Team, $R:$ A language and environment for statistical computing, ( $\mathrm{R}$ Foundation for Statistical Computing, Vienna, Austria, 2020).

[80] D. B. Rubin, Multiple imputation after 18+ years, J. Am. Stat. Assoc. 91, 473 (1996).

[81] S. Van Buuren, Flexible Imputation of Missing Data (CRC Press, Boca Raton, 2018).

[82] J. Honaker, G. King, and M. Blackwell, Amelia II: A Program for Missing Data, J. Stat. Softw. 45, 1 (2011).

[83] C. Choirat, J. Honaker, K. Imai, G. King, and O. Lau, Zelig: Everyone's Statistical Software, Version 5.1.7 (2020).

[84] K. Imai, G. King, and O. Lau, Toward a Common Framework for Statistical Analysis and Development, J. Comput. Graph. Stat. 17, 892 (2008).

[85] See Supplemental Material at http://link.aps.org/ supplemental/10.1103/PhysRevPhysEducRes.18.010107 for results of multiple regression model on physics identity with interaction effects between ISE experiences and identifying as female, Black, and Hispanic.

[86] A. V. Maltese, C. S. Melki, and H. L. Wiebke, The nature of experiences responsible for the generation and maintenance of interest in STEM, Sci. Educ. 98, 937 (2014).

[87] M. J. Mohr-Schroeder, C. Jackson, M. Miller, B. Walcott, D. L. Little, L. Speler, W. Schooler, and D. C. Schroeder, Developing Middle School Students' Interests in STEM via Summer Learning Experiences, School Sci. Math. 114, 291 (2014).

[88] A. Sahin, STEM clubs and science fair competitions: Effects on post-secondary matriculation, J. STEM Educ. 14, 5 (2013), https://www.jstem.org/jstem/index.php/ JSTEM/article/view/1781/1504.

[89] K. Weber, Role models and informal STEM-related activities positively impact female interest in STEM, Technol. Eng. Teach. 71, 18 (2011), https://eric.ed.gov/ ?id=EJ946206.

[90] R. Hite, M. G. Jones, T. Andre, G. Childers, and E. Corin, Female and minority experiences in an astronomy-based science hobby, Cult. Stud. Sci. Educ. 14, 937 (2019).

[91] B. L. Todd and K. Zvoch, The effect of an informal science intervention on middle school girls' science affinities, Int. J. Sci. Educ. 41, 102 (2019).
[92] N. S. King and R. M. Pringle, Black girls speak STEM: Counterstories of informal and formal learning experiences, J. Res. Sci. Teach. 56, 539 (2019).

[93] A. Burrows, M. Lockwood, M. Borowczak, E. Janak, and B. Barber, Integrated STEM: Focus on informal education and community collaboration through engineering, Educ. Sci. 8, 4 (2018).

[94] J. Freese, H. Benedict, S. Carter, K. Hessen, R. Karl, K. Peterson, and C. Scharber, SciGirls code: Creative robotics for tween girls in out of school time, in Proceedings of the 50th ACM Technical Symposium on Computer Science Education (Association for Computing Machinery, New York, NY, 2019), 10.1145/3287324.3287552.

[95] W. Aspray, Recent efforts to broaden informal computer science education, in Participation in Computing (Springer, New York, 2016), pp. 147-163.

[96] A. Gomoll, C. E. Hmelo-Silver, S. Šabanović, and M. Francisco, Dragons, ladybugs, and softballs: Girls' STEM engagement with human-centered robotics, J. Sci. Educ. Technol. 25, 899 (2016).

[97] S. J. Farenga and B. A. Joyce, Intentions of young students to enroll in science courses in the future: An examination of gender differences, Sci. Educ. 83, 55 (1999).

[98] Z. Hazari and G. Potvin, Views on female underrepresentation in physics: retraining women or reinventing physics?, Electronic J. Res. Sci. Math. Educ. 10, 1 (2005), https://scholarlyexchange.org/ojs/index.php/ EJSE/article/view/7739.

[99] National Science Board, Science and Engineering Indicators 2016 (NSB-2016-1) (National Science Foundation, Arlington, VA, 2016).

[100] Education Trust, High School Advanced Science: Physics, Education Trust (2020). Retrieved from: https:// equityinedny.edtrust.org/wp-content/uploads/sites/5/ 2020/01/course-accessupdate_statewide_Physics_01_13_2020.pdf.

[101] U.S. Department of Education, STEM Course Taking, Office for Civil Rights, Civil Rights Data Collection 2015-2016 (2018). Retrieved from: https://www2.ed .gov/about/offices/list/ocr/docs/stem-course-taking.pdf.

[102] K. Spall, S. Barrett, M. Stanisstreet, D. Dickson, and E. Boyes, Undergraduates' views about biology and physics, Res. Sci. Technol. Educ. 21, 193 (2003).

[103] K. Spall, M. Stanisstreet, D. Dickson, and E. Boyes, Development of school students' constructions of biology and physics, Int. J. Sci. Educ. 26, 787 (2004).

[104] D. R. Johnson, E. H. Ecklund, and A. E. Lincoln, Narratives of science outreach in elite contexts of academic science, Sci. Commun. 36, 81 (2014). 